\title{
Influence of injection rate of hyperbaric bupiva- caine on spinal block in parturients: a randomized trial
}

\author{
[L'influence de la vitesse d'injection de bupivacaine byperbare sur la \\ rachianesthésie chez les parturientes: une étude randomisée]
}

Sudha Indu Singh MD FRCPC, Patricia K. Morley-Forster MD FRCPC, Mohammed Shamsah MBbS FRCPC, Ron Butler MD FRCPC

Purpose: A prospective, randomized, double-blind clinical trial was undertaken to determine whether a tenfold difference in the rate of intrathecal injection of bupivacaine would affect sensory block level in parturients. Secondary outcomes included onset of block and the incidence of hypotension and nausea.

Methods: Following Research Ethics Board approval, 90 ASA I and II term parturients scheduled for Cesarean delivery were randomized to receive either fast injection (over four seconds, Group F) or slow injection (over $40 \mathrm{sec}$, Group S) of $0.75 \%$ hyperbaric bupivacaine $12 \mathrm{mg}$ plus morphine $200 \mu \mathrm{g}$. Sensory block, motor block, and blood pressure were assessed every minute for the first $15 \mathrm{~min}$, then every five minutes for the next $20 \mathrm{~min}$. All occurrences of nausea, hypotension (decrease in systolic blood pressure $>30 \%$ ) and ephedrine requirements were recorded.

Results: Forty-three patients in Group $F$ and 42 patients in Group $S$ completed the study. No differences in maximum sensory block height (Group $\mathrm{F}=$ median $\mathrm{T} 2$, interquartile range [T2-T4], Group S = T3 [T2-T4], $P=0.077$ ) or time to achieve block height $(F=9.3 \pm 4.3 \mathrm{~min}, \mathrm{~S}=9.7 \pm 4.7, P=0.64)$ were observed. The frequencies of hypotension (Group $F=35 / 43$, Group $S=32 / 42, P=0.56$ ), ephedrine utilization (Group $F$ $=32 / 43$, Group $S=26 / 42, P=0.21$ ) and nausea (Group $F=$ 15/43, Group $S=16 / 42, P=0.76$ ) were similar.

Conclusion: Rapid intrathecal injection of hyperbaric bupivacaine does not affect spread of spinal anesthesia or the incidence of hypotension and nausea in parturients.

CAN J ANESTH 2007 / 54: 4 / pp 290-295
Objectif : Une étude clinique prospective, randomisée et à double insu a été effectuée afin de déterminer si une vitesse d'injection de bupivacaïne intrathécale multipliée par dix modifie le niveau de bloc sensitif chez les parturientes. Le début du bloc ainsi que l'incidence d'hypotension et de nausée ont été enregistrés comme résultats secondaires.

Méthode : Suite à l'accord du Comité d'éthique en recherche, 90 parturientes ASA l et Il à terme devant subir une césarienne ont été randomisées en deux groupes. Le premier a reçu une injection rapide (en quatre secondes, groupe $F$ ), et le second une injection lente (en $40 \mathrm{sec}$, groupe S) de $12 \mathrm{mg}$ de bupivacaïne hyperbare à $0,75 \%$ plus $200 \mu \mathrm{g}$ de morphine. Les blocs sensitif et moteur ainsi que la tension artérielle ont été évalués chaque minute durant les 15 premières minutes, puis toutes les cinq minutes durant les 20 min suivantes. Les cas de nausées, d'hypotension (diminution de la tension artérielle systolique $>30 \%$ ) et le recours à l'éphédrine ont tous été enregistrés.

Résultats: Des données complètes ont été recueillies chez 43 patientes du groupe $F$ et 42 du groupe $S$. Aucune différence n'a été observée dans la hauteur maximale du bloc sensitif (groupe $F=$ moyenne T2, écart interquartile [T2-T4], groupe $S=T 3$ [T2-T4], $P=0,077)$ ou dans le temps jusqu'à l'obtention de la hauteur du bloc $(F=9,3 \pm 4,3 \mathrm{~min}, S=9,7 \pm 4,7, P=0,64)$. La fréquence d'hypotension (groupe $F=35 / 43$, groupe $S=32 / 42, P=0,56$ ), le recours à l'éphédrine (groupe $F=32 / 43$, groupe $S=26 / 42, P$ $=0,2 I$ ) et l'incidence de nausée (groupe $F=15 / 43$, groupe $S=$ $16 / 42, P=0,76)$ ont été similaires dans les deux groupes.

Conclusion : L'injection intrathécale rapide de bupivacaïne hyperbare n'affecte pas la progression de la rachianesthésie ou l'incidence d'hypotension et de nausée chez les parturientes.

From the Department of Anesthesia and Perioperative Medicine, Schulich School of Medicine, University of Western Ontario, London, Ontario, Canada.

Address correspondence to: Dr. Indu Singh, Department of Anesthesia, St.Joseph's Hospital, 268 Grosvenor St., London, Ontario N6A 4L6, Canada. Phone: 519-646-6000, ext. 64219; Fax: 519-646-6116; E-mail: isingh@uwo.ca

Funded in part by the Department of Anesthesia and Perioperative Medicine, St. Joseph's Hospital, London.

Accepted for publication November 13, 2006.

Revision accepted January 18, 2007. 
$\mathrm{F}$ OR a given drug mass, pregnant patients experience a higher level of spinal anesthesia compared to non-pregnant patients after intrathecal injection of hyperbaric local anesthetic. ${ }^{1,2}$ Spinal anesthesia with hyperbaric bupivacaine is commonly used for elective Cesarean delivery. The recommended spinal block height to ensure patient comfort for Cesarean delivery is T4-6. ${ }^{3}$ Clinically, it is desirable that the spread of local anesthetic through the cerebrospinal fluid (CSF) achieves a sensory level no higher than the T4 dermatome to avoid extensive sympathetic block. ${ }^{4}$ It is also important that the spinal block level be no lower than T6 to avoid patient discomfort during peritoneal manipulation and uterine exteriorization. The effect of injection speed on spread of spinal anesthesia is controversial. Several studies have demonstrated more extensive spread with faster injection ${ }^{5-8}$ while others report either greater spread with slower injection, ${ }^{9-13}$ or no difference. ${ }^{14-18}$ Slow injection of hyperbaric bupivacaine $10 \mathrm{mg}$ over 60 and $120 \mathrm{sec}$ has been shown to reduce the incidence and severity of hypotension during Cesarean delivery under spinal anesthesia. ${ }^{19,20}$

Varying results from the many studies may be attributable to incomplete control of potential confounding variables and other methodogical limitations. As the clinical question is relevant and remains unresolved, we undertook a prospective, randomized, double-blind study, using as the primary outcome the highest level of sensory block achieved. We hypothesized that a tenfold increase in the rate of injection of hyperbaric bupivacaine compared to slow injection over $40 \mathrm{sec}$ would be associated with a higher level of sensory block, at the expense of an increased incidence of hypotension and nausea in parturients undergoing Cesarean delivery. Secondary outcome measures included the onset of sensory block, degree of motor block, use of ephedrine, and the incidence of hypotension and nausea.

\section{Methods}

The Health Sciences Research Ethics Board at the University of Western Ontario approved this investigation. After obtaining written informed consent from each subject, 90 female patients scheduled for non-emergent Cesarean delivery were recruited over the period January 2000 to June 2002. Included were women of American Society of Anesthesiologists (ASA) physical status I and II, who were greater than $18 \mathrm{yr}$ of age presenting with singleton fetuses at term ( $\geq 37$ weeks gestation). Height $<150 \mathrm{~cm}$ or $>$ $180 \mathrm{~cm}$, or any contraindication to spinal anesthesia resulted in exclusion.
Once enrolled, patients were randomized into one of two groups according to a computer-generated table, and allocation concealment was ensured by codes contained in sequentially numbered sealed opaque envelopes. The envelopes were opened immediately prior to drug injection. Patients in group $\mathrm{F}$ received a fast injection of hyperbaric bupivacaine (over four seconds - approximately $0.5 \mathrm{~mL} \cdot \mathrm{sec}^{-1}$ ) and patients in group $\mathrm{S}$ received a slow bupivacaine injection over $40 \mathrm{sec}$ - approximately $0.05 \mathrm{~mL} \cdot \mathrm{sec}^{-1}$. One anesthesiologist was dedicated to patient randomization and administration of the spinal anesthetic, while a second anesthesiologist, who was blinded to group assignment, performed the data collection. All patients were blinded to group assignment.

In the obstetrical operating theatre, following application of routine monitors and insertion of a peripheral 18G iv cannula, a rapid infusion of Ringer's lactate solution $1.5 \mathrm{~L}$ was administered. Patients were placed in the sitting position. After disinfecting the skin and infiltrating with $2 \%$ lidocaine, lumbar puncture was carried out using a 25G Whitacre needle (Becton Dickinson, Franklin Lakes, NJ, USA) through a $20 \mathrm{G}$ introducer at the L2-L3 or L3-L4 interspace in the patient's midline. With the needle orifice pointing cephalad, once free-flow of CSF was obtained, hyperbaric $0.75 \%$ bupivacaine $12 \mathrm{mg}$ (Marcaine, Hospira, St.Laurent, QC, Canada) plus preservative-free morphine $200 \mu \mathrm{g}$ (Morphine LP Epidural, Sandoz, Boucherville, QC, Canada), diluted to a total volume of $2.2 \mathrm{~mL}$ with CSF, was injected. The start of injection was recorded as time 0 , and the speed of injection was governed according to group assignment. Immediately after injection, the women were placed supine with a wedge under the right hip for left uterine displacement. A fetal heart rate monitor was then applied until the start of surgery. Oxygen was administered at $4 \mathrm{~L} \cdot \mathrm{min}^{-1}$ via Hudson mask.

The sensory level of spinal anesthesia was assessed bilaterally in the anterior axillary line by pinprick, using a short bevelled $25 \mathrm{G}$ needle, and was recorded at baseline prior to spinal injection, then every minute for the first $15 \mathrm{~min}$ after injection, and every five minutes for the next $20 \mathrm{~min}$, and at $45 \mathrm{~min}$. Blood pressure, heart rate, and the extent of motor block were recorded at the same measurement intervals. Anesthesia was defined as the inability to detect a sharp pinprick. Motor block of the lower limbs was evaluated using the Bromage score $(0=$ ability to raise extended leg; 1 = inability to raise extended leg, ability to flex the knee; 2 = inability to flex the knee, ability to flex the ankle; 3 = inability to flex the knee and ankle). Assessments of motor block were made immediately 
TABLE I Patient demographics and clinical characteristics

\begin{tabular}{lll}
\hline Group & Fast $(n=43)$ & Slow $(n=42)$ \\
\hline Age $(\mathrm{yr})$ & $31.9 \pm 4.2$ & $30.0 \pm 4.9$ \\
Gestation (week) & $38.9 \pm 1.1$ & $38.8 \pm 1.1$ \\
Weight $(\mathrm{kg})$ & $85.0 \pm 14.8$ & $84.3 \pm 12.5$ \\
Height $(\mathrm{cm})$ & $161.4 \pm 5.5$ & $161.1 \pm 6.4$ \\
$\begin{array}{l}\text { Body mass index }\left(\mathrm{kg} \cdot \mathrm{m}^{2}\right) \\
\begin{array}{l}\text { Baseline systolic blood pressure } \\
(\mathrm{mmHg})\end{array}\end{array}$ & $32.5 \pm 5.3$ & $32.2 \pm 5.5$ \\
\hline
\end{tabular}

Data are expressed as mean \pm SD. There were no significant differences between groups.

after assessment of anesthesia levels. Blood pressure was measured using an automated non-invasive blood pressure monitor (Datex-Ohmeda, Bromma, Sweden) and heart rate was measured from the pulse oximeter (Datex-Ohmeda, Bromma, Sweden). Hypotension was defined as a decrease of at least $30 \%$ below baseline systolic blood pressure (SBP), or an absolute value < $100 \mathrm{mmHg}$. Hypotension was treated with ephedrine boluses $5 \mathrm{mg}$ iv every two minutes until SBP returned to a value $>100 \mathrm{mmHg}$. Ephedrine requirements, nausea, and antiemetic use were recorded. Antiemetics were administered at the discretion of the attending anesthesiologist.

\section{Statistical considerations}

Sample size calculation was based on a pilot study ( $n=16)$ which demonstrated that with a standard deviation of 1.6 dermatomal levels in the upper level of sensory block, 38 patients would be required per group to have an $80 \%$ probability of detecting a difference of one dermatome between group means at the 0.05 level of significance using two-tailed $P$ values. We considered that a one dermatome difference in sensory block height was clinically significant in the mid-upper thoracic region with respect to extent of sympathetic blockade and impairment of the cardioaccelerator fibres. Maximum sensory block height and maximum motor block were compared using a Wilcoxon two-sample test. To compare the level of sensory block between groups, the dermatomes L5 to Tl were coded from lowest to highest as 1-17. Times to maximum block height, to maximum motor block, to first hypotensive event and to lowest SBP were compared using unpaired Student's $t$ tests. Since variances were not equal for time to T6 block, comparison was based on the log-transformed times. Lowest SBP and duration of hypotension in the two groups were compared using an unpaired $t$ test. Frequencies of hypotension and nausea were compared using the Chi-square statistic. A $P$ value $<0.05$ was considered statistically significant.

\section{Results}

Ninety patients were enrolled and randomized (45 patients in each group). Five patients (two in group $\mathrm{F}$ and three in group $S$ ) were subsequently excluded. Two patients (one in each group) did not receive the correct amount of bupivacaine during spinal injection. Three patients (one in group $\mathrm{F}$ and two in group $\mathrm{S}$ ) were lost to follow-up because of incomplete data sheets. Data from 43 patients in group $\mathrm{F}$ and 42 patients in group $S$ were available for analysis. Results are presented for these 85 patients.

Anesthesia was satisfactory for all women. The two groups were similar with respect to age, height, weight, gestation and baseline blood pressures (Table I).

The block characteristics of the two groups are shown in Table II. Both groups had median highest sensory block levels above T4. The median highest sensory block level was $\mathrm{T} 2$, interquartile range [T2-T4] in group F and T3, [T2-T4] in group S $(P$ $=0.077$, Wilcoxon two-sample test). Time taken to reach highest sensory block level was similar in both groups $(9.3 \pm 4.3 \mathrm{~min}$ in group $\mathrm{F}$ vs $9.7 \pm 4.7 \mathrm{~min}$ in group $S, P=0.64$ unpaired $t$ test). The times to ready for Cesarean delivery (measured as time to T6 sensory block) were also similar in the two groups $(5.2 \pm 1.9$ min in group $\mathrm{F}$ vs $6.6 \pm 3.5 \mathrm{~min}$ in group $S, P=0.11)$.

No difference in time to maximum motor block was observed between groups $(4.4 \pm 3.2 \mathrm{~min}$ in group F ps $5.0 \pm 2.5 \mathrm{~min}$ in group $\mathrm{S}, P=0.34$, unpaired $t$ test). All patients achieved a modified Bromage score of 3 .

Hemodynamic data are presented in Table III. The groups were similar with respect to the incidence of hypotension, the lowest recorded SBP, and times to lowest SBP. Cumulative doses of administered ephedrine did not differ between groups, while the incidence of nausea ( $15 / 43$ in group $F$ vs $16 / 42$ in group $S, P=0.76$, Chi square test) and the incidence of antiemetic utilization were also similar in the two groups $(10 / 43$ in group $\mathrm{F}$ vs $11 / 42$ in group $S, P=$ 0.72 , Chi-square test).

\section{Discussion}

It is controversial as to whether the speed of intrathecal injection of local anesthetic affects sensory block height. The choice of injection rate usually depends on the preference of the anesthesiologist. We were unable to confirm our hypothesis that rapid injection of intrathecal hyperbaric bupivacaine would increase the sensory block level in pregnant patients at term. A tenfold difference in the intrathecal injection rate of $12 \mathrm{mg}$ of hyperbaric bupivacaine (four seconds 
TABLE II Spinal block characteristics

\begin{tabular}{llll}
\hline Group & Fast $(n=43)$ & Slow $(n=42)$ & P value \\
\hline Maximum sensory block level & T2 & T3 & 0.077 \\
Range & (T1-T4) & (T1-T6) & \\
Quartile & {$[\mathrm{T} 2-\mathrm{T} 4]$} & {$[\mathrm{T} 2-\mathrm{T} 4]$} & 3 \\
Maximum motor block (Bromage score) & 3 & $6.6 \pm 3.5$ & 0.11 \\
Time to T6 sensory block (min) & $5.2 \pm 1.9$ & $9.7 \pm 4.7$ & 0.64 \\
Time to maximum sensory block level (min) & $9.3 \pm 4.3$ & $5.0 \pm 2.5$ & 0.34 \\
Time to maximum motor block (min) & $4.4 \pm 3.2$ &
\end{tabular}

Data for maximum sensory block level expressed as mean dermatome, (range), [quartiles]. Data for time to T6 block, maximum sensory and motor block are presented as mean \pm SD. Since the variances were not equal for time to T6 sensory block, comparison was based on the log-transformed times.

TABLE III Hemodynamic characteristics after intrathecal injection

\begin{tabular}{llll}
\hline Group & Fast $(n=43)$ & Slow $(n=42)$ & P value \\
\hline Incidence of hypotension $(n)$ & 35 & 32 & 0.56 \\
Lowest SBP (mmHg) & $83.2 \pm 10.3$ & $82.6 \pm 13.0$ & 0.91 \\
Time to first hypotensive episode (min) & $3.7 \pm 2.3$ & $4.5 \pm 2.3$ & 0.20 \\
Time to lowest SBP (min) & $5.6 \pm 2.8$ & $5.8 \pm 2.4$ & 0.70 \\
Total time hypotensive (min) & $4.0 \pm 1.4$ & $26 \pm 1.6$ & 0.87 \\
Ephedrine use $(n)$ & 32 & $15.0 \pm 12.5$ & 0.22 \\
Total dose of ephedrine (mg) & $17.4 \pm 11.2$ & 16 & 0.50 \\
Nausea $(n)$ & 15 & 11 & 0.76 \\
Antiemetic use $(n)$ & 10 & 0.72 \\
\hline
\end{tabular}

Data are expressed as mean \pm SD or as number. There were no significant differences between groups with respect to hemodynamic characteristics and antiemetic use after intrathecal injection. $\mathrm{SBP}=$ systolic blood pressure.

vs $40 \mathrm{sec}$ ) affected neither the onset time nor the maximum sensory block level attained. Both groups achieved median sensory block levels higher than the T4 dermatome. Post hoc power analysis revealed that based on a difference of one dermatome, using the variability observed in this study, the statistical power was $98 \%$.

There have been many clinical studies comparing effects of different spinal injection rates on sensory block level with mixed results. ${ }^{5-21}$ Conflicting results from these studies may be due to differences in spinal needles used, local anesthetics injected, temperature of solutions injected, injection rates performed, and patient populations studied. Slow injection rates have varied from $0.06 \mathrm{~mL} \cdot \mathrm{sec}^{-1}$ to $0.02 \mathrm{~mL} \cdot \mathrm{sec}^{-1}$. Most studies of injection speed using hyperbaric solutions of local anesthetic have not found a difference in sensory levels of spinal anesthesia. ${ }^{13,15,16}$ However, these studies were done in non-pregnant patients. Pregnancy is associated with higher levels of sensory block after spinal injection of hyperbaric solutions. ${ }^{1,2}$ Factors that may contribute to a higher block in parturients include changes in spine curvature, increased intra-abdominal pressure, distension of epidural veins and decreased spinal and epidural spaces. ${ }^{2,22}$ There may also be a progesterone-related increase in neuronal sensitivity. ${ }^{23}$

Two recent studies comparing hemodynamic effects of different spinal injection rates have found that slow injection of hyperbaric bupivacaine decreases hypotension during Cesarean delivery under spinal anesthesia. Simon and co-investigators compared injection rates of $0.26 \mathrm{~mL} \cdot \mathrm{sec}^{-1}$ vs $0.03 \mathrm{~mL} \cdot \mathrm{sec}^{-1}$ and found that slow injection reduced the incidence of hypotension from $92 \%$ to $68 \% .{ }^{20}$ This study differed from ours in that maximum sensory block levels were not compared, injections were carried out in the left lateral decubitus position, injection speeds were different, and their study was not randomized. Another study compared the effects of two different injection speeds $(0.17$ $\mathrm{mL} \cdot \mathrm{sec}^{-1}$ vs $\left.0.06 \mathrm{~mL} \cdot \mathrm{sec}^{-1}\right)$ of intrathecal hyperbaric bupivacaine on the incidence of hypotension in parturients undergoing Cesarean delivery. ${ }^{19}$ Injections were done with patients in the sitting position. The number of patients with SBP lower than $100 \mathrm{mmHg}$ was significantly lower in the slow injection group. This was a randomized clinical trial, but it was not doubleblinded and maximum sensory block levels were not compared. Unlike these two studies, the incidence of 
hypotension in our investigation was similar in both groups $(81.4 \%$ in group $\mathrm{F}$ and $76.2 \%$ in group $\mathrm{S}$ ) as were the doses of ephedrine administered.

\section{Study limitations}

A potential limitation of our study is that intrathecal injections were carried out with patients in the sitting position. Because patients were positioned supine immediately after injection, the duration spent in the sitting position was different in the two groups, so that patients in group $S$ were sitting $36 \mathrm{sec}$ longer. This may have influenced the trend to a lower block in group S. However, in a clinical study of nonpregnant patients receiving intrathecal hyperbaric bupivacaine, sitting for 25 min did not affect sensory level as compared with sitting for two minutes. ${ }^{24}$

It is also possible that since the injections were administered manually, the injection speeds may not have been uniform within the groups. A tenfold difference may not have been reliably achieved between the two groups. Some studies used electronic pumps to maintain accurate injection speeds. ${ }^{5,11,21}$ We felt that use of such devices would be cumbersome and not representative of clinical practice in a busy obstetric unit. A tenfold difference in injection speed of intrathecal hyperbaric bupivacaine may not have been of sufficient magnitude to detect different levels of sensory blocks. A much slower injection speed than 0.05 $\mathrm{mL} \cdot \mathrm{sec}^{-1}$ may have been necessary. Bourke et al. found in their in vitro study evaluating speed of injection in a spinal canal model, that injection through a $25 \mathrm{G}$ Whitacre needle at rates greater than $0.017 \mathrm{~mL} \cdot \mathrm{sec}^{-1}$ was associated with varying degrees of turbulence. ${ }^{25}$ However, we considered that our slow injection rate of $0.05 \mathrm{~mL} \cdot \mathrm{sec}^{-1}$ was within a clinically relevant range. Another in vitro study of hyperbaric dye distribution characteristics after pencil point needle injection in a spinal cord model suggests that transition from laminar to a more turbulent flow occurs at $6 \mathrm{~mL} \cdot \mathrm{min}^{-1}$ $\left(0.1 \mathrm{~mL} \cdot \mathrm{sec}^{-1}\right) .{ }^{26} \mathrm{In}$ our study, it is likely that group $\mathrm{F}$ patients experienced a turbulent flow during local anesthetic injection, whereas group $S$ patients should have experienced non-turbulent laminar flow. However, no significant difference in the highest sensory block level was observed between groups.

Our study is the first randomized double-blind clinical trial to compare the effects of a tenfold difference in clinically relevant rates of intrathecal injection of hyperbaric bupivacaine in term parturients undergoing Cesarean delivery. No difference in the levels of sensory anesthesia were observed, and the frequencies of hypotension and nausea were not influenced by the speed of injection. In conclusion, when injecting intrathecal hyperbaric bupivacaine for Cesarean delivery in term parturients, the speed of injection is not an important determinant of the maximum spread of spinal anesthesia.

\section{Acknowledgements}

The authors sincerely thank all anesthesiologists, obstetricans, and obstetrical nursing staff at St. Joseph's Hospital in London, Ontario. We are also grateful for the expert assistance with statistical analysis provided by Mr. Larry Stitt, of the Clinical Epidemiology and Biostatistics Department, University of Western Ontario.

\section{References}

1 Fassoulaki A, Gatzon V, Pteropoulos G, Siafaka I. Spread of subarachnoid block, intraoperative local anesthetic requirements and postoperative analgesic requirements in caesarean section and total abdominal hysterectomy. Br J Anaesth 2004; 93: 678-82.

2 Hirabayashi $\Upsilon$, Shimizu R, Saitoh K, Fukuda H. Spread of subarachnoid hyperbaric amethocaine in pregnant women. Br J Anaesth 1995; 74: 384-6.

3 Bernards CM. Epidural and spinal anesthesia. In: Barash PG, Cullen BF, Stoelting RK (Eds).Clinical Anesthesia, $5^{\text {th }}$ ed. Lippincott Williams \& Wilkins; 2006: 701.

4 Bandi E, Weeks S, Carli F. Spinal block levels and cardiovascular changes during post-cesarean transport. Can J Anesth 1999; 46: 736-40.

5 Horlocker TT, Wedel DJ, Wilson PR. Effect of injection rate on sensory level and duration of hypobaric bupivacaine spinal anesthesia for total hip arthroplasty. Anesth Analg 1994; 79: 773-7.

6 Chin KW, Chin NM, Chin MK. Spread of spinal anaesthesia with $0.5 \%$ bupivacaine: influence of the vertebral interspace and speed of injection. Med J Malaysia 1994; 49: 142-8.

7 Atchison SR, Wedel DJ, Wilson PR. Effect of injection rate on level and duration of hypobaric spinal anesthesia. Anesth Analg 1989; 69: 496-500.

8 McClure JH, Brown DT, Wildsmith JA. Effect of injected volume and speed of injection on the spread of spinal anaesthesia with isobaric amethocaine. Br J Anaesth 1982; 54: 917-20.

9 Hanazaki M, Hashimoto M, Nogami S, Kusodo K, Aono $H$, Takeda $A$. Effect of injection speed on sensory blockade in spinal anesthesia with $0.5 \%$ hyperbaric tetracaine (Japanese). Masui 1997; 46: 777-82.

10 Tuominen M, Pitkanen M, Rosenberg PH. Effect of speed of injection of $0.5 \%$ plain bupivacaine on the spread of spinal anaesthesia. Br J Anaesth 1992; 69: 148-9. 
11 Shih HY, Soga T, Sakai H, Okumura F, Lin SY. Infusion speed as a factor to influence the analgesic level of spinal anesthesia-hypobaric solution of tetracaine (Chinese). Ma Zui Xue Za Zhi 1990; 28: 171-5.

12 Stienstra R, Van Poorten F. Speed of injection does not affect the subarachnoid distribution of plain bupivacaine 0.5\%. Reg Anesth 1990; 15: 208-10.

13 Janik R, Dick W, Stanton-Hicks M. The effect of the injection speed on the blockade characteristics of hyperbaric bupivacaine and tetracaine in spinal anesthesia (German). Reg Anaesth 1989; 12: 63-8.

14 Nasubara H, Obmi S, Yokoyama K. Influence of injection speed on the spread of $4 \mathrm{ml}$ of $0.5 \%$ isobaric bupivacaine in spinal anesthesia (Japanese). Masui 2000; 49: 1363-6.

15 Casati A, Fanelli G, Cappelleri G, et al. Effects of speed of intrathecal injection on unilateral spinal block by $1 \%$ hyperbaric bupivacaine. A randomized, doubleblind study. Minerva Anestesiol 1999; 65: 5-10.

16 Casati A, Fanelli G, Cappelleri G, Leoni A, Berti M, Aldegheri $G$. Does speed of intrathecal injection affect the distribution of $0.5 \%$ hyperbaric bupivacaine? $\mathrm{Br} \mathrm{J}$ Anaesth 1998; 81: 355-7.

17 Bucx MJ, Kroon JW, Stienstra R. Effect of speed of injection on the maximum sensory level for spinal anesthesia using plain bupivacaine $0.5 \%$ at room temperature. Reg Anesth 1993; 18: 103-5.

18 Van Gessel EF, Praplan J, Fuchs T, Forster A, Gamulin $Z$. Influence of injection speed on the subarachnoid distribution of isobaric bupivacaine 0.5\%. Anesth Analg 1993; 77: 483-7.

19 Bouchnak M, Belhadj N, Chaaoua T, Azaiez W, Hamdi $M$, Maghrebi $H$. Spinal anaesthesia for cesarean section: does injection speed have an effect on incidence of hypotension? (French). Ann Fr Anesth Reanim 2006; 25: 17-9.

20 Simon L, Boulay G, Ziane AF, et al. Effect of injection rate on hypotension associated with spinal anesthesia for cesarean section. Int J Obstet Anesth 2000; 9: $10-4$.

21 Anderson L, Walker J, Brydon C, Serpell MG. Rate of injection through Whitacre needles affects distribution of spinal anaesthesia. Br J Anaesth 2001; 86: 245-8.

22 Jawan B, Lee JH, Chong ZK, Chang CS. Spread of spinal anaesthesia for caesarean section in singleton and twin pregnancies. Br J Anaesth 1993; 70: 639-41.

23 Butterworth JF $4^{\text {th }}$, Walker FO, Lysak SZ. Pregnancy increases median nerve susceptibility to lidocaine. Anesthesiology 1990; 72: 962-5.

24 Povey HM, Olsen PA, Pibl H. Spinal analgesia with hyperbaric $0.5 \%$ bupivacaine: effects of different patient positions. Acta Anaesthesiol Scand 1987; 31: 616-9.

25 Bourke DL, Sprung J, Harrison C, Thomas P. The drib- ble speed for spinal anesthesia. Reg Anesth 1993; 18 : 326-7.

26 Holman SJ, Robinson RA, Beardsley D, Setwart S, Klein $L$, Stevens $R$. Hyperbaric dye solution distribution characteristics after pencil-point needle injection in a spinal cord model. Anesthesiology 1997; 86: 966-73. 